\title{
ESTRUCTURA AGRARIA Y DINÁMICA DE LA POBLACIÓN EN BRASIL Y EN MÉXICO
}

\author{
Waldomiro Pecht \\ Centro Latinoamericano de Demografía
}

\section{INTRODUCCIÓN}

EL oB JETIVo central de la investigación a que se refiere este documento, es señalar los rasgos principales del proceso de crecimiento y transferencia de fuerza de trabajo (FT) del campo hacia la ciudad en Brasil y México. El porqué del análisis de estos países estriba en que son los principales de América Latina en cuanto al volumen de poblaeión y donde además se encuentran grandes contingentes de población rural y un proceso intenso de migración del campo a la ciudad. Estos elementos por sí mismos serían suficientes para justificar el interés del estudio en estos países.

Sin embargo, además se agrega el hecho de que son países que han tenido una dinámica social muy distinta en lo que respecta a la estructura agraria. En cuanto a México, pasó por un proceso intenso y violento de transformaciones en el campo; mientras en Brasil se mantuvo una relativa tranquilidad, interrumpida sólo por hechos aislados, sin mayores consecuencias para las estructuras vigentes en el agro. Señalaremos algunas evidencias estructurales del sector rural de ambos países para después presentar un enfoque de las relaciones económicas y sociales que explicarían o estarían asociadas a la dinámica poblacional observada.

\section{Algunos indicadores de la estructura AgraRia}

Con objeto de tener algunos elementos que permitieran apreciar ciertos rasgos de la estructura agraria y de las condiciones en que los trabajadores actúan en los procesos productivos, se presentan a continuación algunas características que dan una idea general del nivel de desarrollo de las fuerzas productivas en el campo, en los dos países. Para efectos también de apreciar mejor el significado de cada cifra, se presenta alguna información sobre Estados Unidos para tener algunos puntos de referencia que permitan juzgar los niveles de los países que se analizan. La comparación se hace con Estados Unidos por ser el país más represen- 
tativo del desarrollo capitalista, el cual es utilizado con frecuencia como paradigma, de manera implícita o explícita, de las economías de mercado y porque presenta además algunos rasgos estructurales convenientes para tomarlo como punto de referencia en nuestro análisis: extensión territorial, gran población y por haberse registrado además (y proporcionado) algunas experiencias históricas comunes a los países de América Latina.

Se presentan primero datos sobre la participación del producto agrícola en la formación del producto nacional y algunas indicaciones de la productividad de los trabajadores agrícolas así como la relación entre producto y número de trabajadores. También se analiza el aprovechamiento de las tierras a través del tipo de uso y, por último, se considera la distribución de las propiedades agrícolas según el tamaño, área y tipo de tenencia, así como datos sobre la mecanización. Estos elementos permitirán visualizar la existencia eventual de diferencias significativas entre los países, indicio de que la investigación profundizada en el mar. co de la estructura agraria puede resultar un valioso aporte a la comprensión de la dinámica de la población rural.

En primer lugar, se destaca la importancia que tiene el sector agrícola en el producto nacional (véase el cuadro 1).

\section{Cuadro 1}

Producto interno bruto (PIB) De la agricultura, silvicultura, CAza $Y$ PESCA (A COSTO DE LOS FACTORES PARA 1970, MEDIA DEL TRIENIO 1969, 1970 Y 1971)

\begin{tabular}{|c|c|c|c|c|}
\hline & Brasil & Maxicob & $\therefore$ & $\begin{array}{l}\text { Estadoe } \\
\text { Unidos }\end{array}$ \\
\hline $\begin{array}{c}\text { I - PIB on la agrioul tura, } \\
\text { silvioultura, osea } y \\
\text { pesca }\end{array}$ & 624.2 & 34102 & & 25624 \\
\hline II - PIB nacional & 4259.5 & 280302 & & 606810 \\
\hline I/II (porciontos) & 19.3 & 12.2 & & 3.2 \\
\hline
\end{tabular}

Fuente: Brasil y México: cepal, Cuentas nacionales; Estados Unidos: América en cifras, 1972, Washington, OEA, cuadro 342.14 .

a En millones de cruzeiros de 1960.

- En millones de pesos de 1960 .

c Ingreso nacional en millones de dólares corrientes.

Como se puede apreciar, el sector agrícola es mucho más importante en Brasil que en México en cuanto a su contribución al PrB. Entretanto se aprecia una diferencia muy considerable entre estos países y Estados Unidos.

Veamos el nivel de productividad de los trabajadores agrícolas. Se considera la población económicamente activa (PEA) agrícola en vez de los trabajadores ocupados de manera efectiva, por ser la PEA un concepto más homogéneo, además de que interesa destacar las diferencias relativas y no los valores absolutos de la productividad. 
Cuadro 2

Productividad agrícola, 1970

\begin{tabular}{|c|c|c|c|c|}
\hline & & Bras il & Mexico & $\begin{array}{r}\text { Estados } \\
\text { Unidos }\end{array}$ \\
\hline I & $\begin{array}{l}\text { PIB africola (en millones } \\
\text { do dolares) }\end{array}$ & 6526.7 & 4143.7 & 25624.0 \\
\hline II & $\begin{array}{l}\text { Poblacibn econbricanente } \\
\text { activa abxicole (miles) }\end{array}$ & 13071.4 & 5283.7 & 2840.5 \\
\hline \multirow[t]{2}{*}{ III } & I/II (en dolares per capita) & 499.3 & 784.2 & 9020.9 \\
\hline & $\$$ (Estados Unidoe $=100)$ & 5.5 & 8.7 & 100.0 \\
\hline
\end{tabular}

Fuente: PIB: Brasil y México: cepal, Cuentas nacionales; Estados Unidos: América en cifras, 1972, cuadro 342-14.

PEA: Brasil y México: Censos de población; Estados Unidos: América en cifras, 1972, cuadro 408-02.

Es claro que la productividad del trabajador agrícola mexicano es bastante superior al de Brasil y en ambos es muy inferior a la del trabajador de Estados Unidos.

Veamos ahora algunos rasgos de la distribución de las tierras en el agro, según clases de aprovechamiento y también según tamaño de las propiedades. Se utilizan algunos datos de los censos agrícolas de 1960 ya que no se dispuso de informaciones completas de los censos de 1970.

En primer lugar, se aprecia en el cuadro 3, la distribución de las tierras según clase de aprovechamiento es bastante similar en Brasil y México. Hay que destacar entre tanto una diferencia muy importante en la relación entre tierras destinadas a cultivos permanentes y tierras de labranza con cultivos temporales. Al comparar ambos países con Estados Unidos, se tornan más evidentes las diferencias básicas que expresan la relación cultivos temporales y cultivos permanentes; también destacan de manera evidente las diferencias en cuanto a la reducida ocupación de tierras en bosque, montes y las clasificadas como de "otras clases" en los Estados Unidos.

Al considerar otro rasgo importante (la distribución de las tierras según tamaño) y agrupar los datos para disponer de una clasificación que permitiera visualizar aspectos estructurales, éstos se organizaron según tres categorías de tamaño:

a) De 0 a menos de 10 hectáreas;

b) De 10 a menos de 100 hectáreas;

c) De 100 y más hectáreas;

Estas categorías de tamaño se asimilaron a los conceptos de pequeñas, medianas y grandes propiedades, respectivamente. También, de manera preliminar, se podrían asimilar las pequeñas a los conceptos de minifundios y las grandes a los de latifundios. Además, por los datos disponibles en el caso de Estados Unidos sólo se pudieron organizar categorías aproximadas a las anteriores, esto es: 
Cuadro 3

SUPERFICIE DE LAS EXPLOTACIONES AGROPECUARIAS, SEGÚN UTILIZACIÓN DE LA TIERRA (porcientos)

\begin{tabular}{|c|c|c|c|}
\hline $\begin{array}{l}\text { Unidades de } \\
\text { explotaoibn }\end{array}$ & $\begin{array}{l}\text { Brasil } \\
(1960)\end{array}$ & $\begin{array}{l}\text { Mérico } \\
(1960)\end{array}$ & $\begin{array}{r}\text { Estadoa } \\
\text { Unidos } \\
(1964)\end{array}$ \\
\hline Total & 100.0 & 100.0 & 100.0 \\
\hline $\begin{array}{l}\text { Dedicadas a cultivos } \\
\text { permanentes }\end{array}$ & 3.1 & 0.8 & 0.4 \\
\hline \multicolumn{4}{|l|}{ Do labranza } \\
\hline Con cultiros temporales & 8.4 & 6.1 & 25.5 \\
\hline In descanso & - & 6.2 & 5.0 \\
\hline Otras clases & 0.2 & 1.0 & 3.0 \\
\hline \multicolumn{4}{|l|}{$\begin{array}{l}\text { Dedicadas a praderas y } \\
\text { pastizales pormanentes }\end{array}$} \\
\hline Pastos oul tirados & 8.0 & 46.8 & 5.2 \\
\hline Pastos naturales & 40.9 & & 44.2 \\
\hline Wh wontes o bosques & 23.2 & 25.8 & 13.3 \\
\hline De otras clased & 16.2 & 13.3 & 3.6 \\
\hline
\end{tabular}

Fuente: Cuadro A-1 del Anexo Estadístico.

a) Pequeñas propiedades: de 0 a menos de 20.24 hectáreas.

b) Propiedades medianas: de 20.24 a 105.22 hectáreas.

c) Grandes propiedades: de 105.22 y más hectáreas.

Los resultados aparecen en el cuadro 4.

Al comparar el número de propiedades según su tamaño, Brasil aparece con pocas propiedades grandes y muchas medianas y pequeñas. En México, por el contrario, surge una gran cantidad de propiedades pequeñas y muy pocas medianas y grandes. Estados Unidos difiere del Brasil y México: aparece con pocas propiedades pequeñas y grandes y muchas de tamaño mediano.

\section{Cuadro 4}

Distribución de LAS PROPIEDAdes SEGúN NúMERo Y TAMAÑo (porcientos)

\begin{tabular}{|c|c|c|c|c|c|c|c|}
\hline & & \multicolumn{2}{|c|}{ Brasil (1960) } & \multicolumn{2}{|c|}{ Móxico (196) } & \multicolumn{2}{|c|}{$\begin{array}{c}\text { Es tados } \\
\text { Unidos (1964) } \\
\end{array}$} \\
\hline & & Nimero & Area & himero & Area & Notnero & srea \\
\hline I & Pequeañas & 44.9 & 2.4 & 72.8 & 1.2 & 26.0 & 1.6 \\
\hline II & Medianas & 44.8 & 19.0 & 19.2 & 5.2 & 48.5 & 18.3 \\
\hline \multirow[t]{2}{*}{ III } & Grandes & 10.3 & 78.6 & 8.0 & 93.6 & 25.5 & 80.1 \\
\hline & Total & 100.0 & 100.0 & 100.0 & 100.0 & 100.0 & 100.0 \\
\hline
\end{tabular}

Fuente: Cuadro A-2 del Anexo Estadístico. 
Ahora bien, si se considera la distribución de las propiedades según el tamaño en términos de superficie, aparece en los tres países una gran concentración de tierras en las grandes propiedades y muy poca tierra en las pequeñas, con una distribución similar de áreas en propiedades medianas en Brasil y Estados Unidos. Para México se destaca una menor proporción de áreas en propiedades de tamaño mediano, lo que acentúa la concentración de tierras en las grandes propiedades.

Sin embargo, es necesario mencionar que las cifras señaladas para México distorsionan mucho la realidad de la distribución de tierras según tamaño. Es así como mucha de la tierra que aparece en predios grandes (de más de 100 hectáreas principalmente) son en verdad unidades ejidales y comunales. Una solución aproximada para el problema es considerar cada ejidatario con tierra como una unidad de producción (esto es correcto si se tiene en cuenta que las parcelas ejidales son explotadas en forma independiente por cada ejidatario en la casi totalidad de los casos). De esta forma, tendríamos que agregar 1365141 predios, que menciona el Censo Agrícola y que fueron considerados en la tabulación del cuadro 4, 1505097 (que corresponderían a 1523796 "parcelas ejidales" de ejidatarios con tierra, menos 18699 que ya están considerados como predios ejidales en los 1365141 ). Esto implica que el número de predios sería de 2851539 .

El problema es saber cómo se distribuyen por grupos de tamaño las parcelas ejidales. Esa información no figura en los volúmenes censales, pero se sabe que en su mayoría son superficies de menos de diez hectáreas, y una proporción reducida de más de diez hectáreas. Esto significa alterar de manera sustancial la distribución que aparece en el cuadro 4 para México. Por desgracia, no existen datos disponibles por el momento para calcular con exactitud la distribución. Tenemos, sin embargo, álgunos indicadores. A partir de un trabajo publicado en México, ${ }^{1}$ se puede estructurar la distribución que considera en exclusiva tierras de labor y que aparece en el cuadro 5 .

\section{Cuadro 5}

MÉxico: Distribución de las tierRas agrícolas de labor SEgúN NÚMERO Y SUPERFICIE DE LOS PREDIOS, 1960 (porcientos)

\begin{tabular}{rrr}
\hline Superficie (hectareas) & Mtmero & Srea \\
\hline I) Hasta 10 & 84.9 & 37.8 \\
II) De 10 a 100 & 14.5 & 32.9 \\
III) too y pks & 0.6 & 29.3 \\
& 0.6 & 100.0 \\
\hline
\end{tabular}

Fuente: M. Ayuilera Gómez, La reforma agraria en el desarrollo económico de México, México, Instituto Mexicano de Investigaciones Agrarias, 1969.

1 M. Aguilera Gómez, La reforma agraria en el desarrollo económico de México, México, Instituto Mexicano de Investigaciones Agrarias, 1969, p. 162. 
Estos valores alteran de manera sustancial, en lo que respecta a México, las inferencias que podríamos obtener a partir del cuadro 4. Así, disminuye de manera sensible la superficie de los predios considerados antes con más de 100 hectáreas; aumenta de manera extraordinaria la proporción de predios pequeños y también se fortalece el grupo de predios de tamaño mediano. Tales valores dejan traslucir los efectos de la reforma agraria en México, que han diferenciado de manera palpable la estructura de ese país en relación con Brasil y Estados Unidos.

Un indicador de la manera en que las tierras se distribuyen según el tipo de tenencia, aparece en el cuadro 6.

\section{Cuadro 6}

SUPERFICIE DE LAS EXPLOTACIONES AGROPECUARIAS POR RÉGIMEN DE TENENCIA

(porcientos)

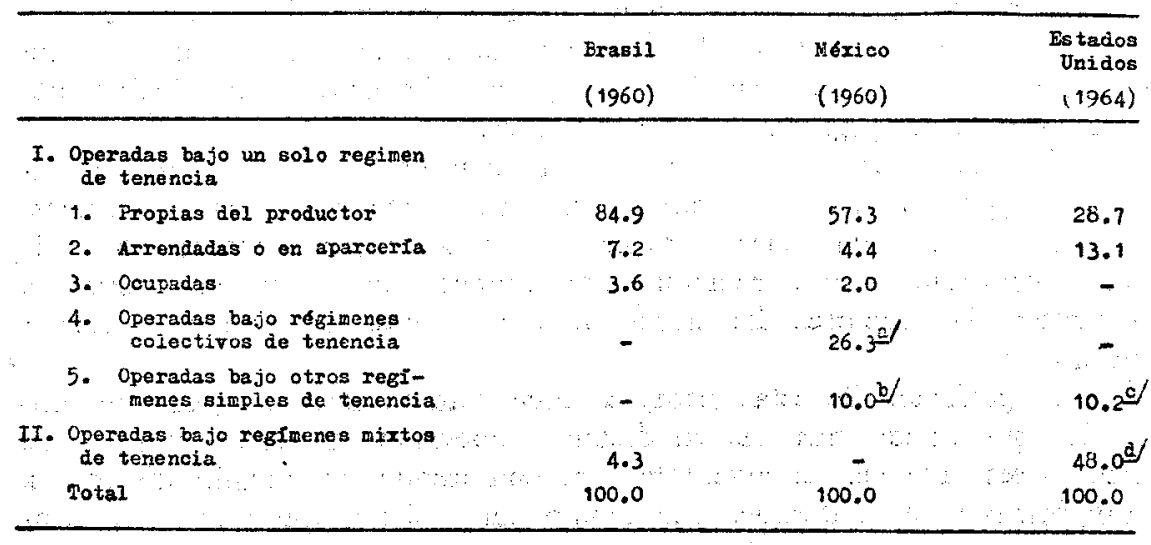

Fuente: Cuadro A-3 del Anexo Estadístico.

a Predios operados por el "Presidente del Comisariado Ejidal".

b Comprende predios operados por el "Presidente de la Comunidad".

c Explotaciones operadas por "administradores".

d Explotaciones operadas por "propietarios-arrendatarios".

El cuadro revela con claridad diferencias marcadas en la estructura de la tierra entre los tres países. Así, se observa que la proporción de tierras propiedad del productor es mucho más alta en Brasil $(85 \%)$ que en México $(57 \%)$. La diferencia radica de manera básica en la gran proporción de tierras que en México son operadas en formas colectivas, de manera principal ejidos. En Estados Unidos la proporción de tierras propias del productor es la menor de los tres países $(29 \%)$, debido a la existencia de mucha tierra utilizada bajo regímenes mixtos de tenencia, que combinan de manera principal propietarios y arrendatarios $(48 \%)$ y a arrendatarios puros $(13 \%)$.

Estas cifras denotan rasgos que caracterizan a los tres países: 
a) El predominio en Brasil de propietarios como responsables de la producción;

b) Una proporción importante en México de la propiedad colectiva (si bien es muy fuerte la participación de los propietarios como responsables) ;

c) La presencia en Estados Unidos de arrendatarios.

Es interesante señalar que la elevada proporción del arrendamiento en la agricultura es un rasgo fundamental del desarrollo de relaciones capitalistas de producción en el agro. Esto se debe a que la tierra, a través del arrendamiento, adquiere con más claridad el estatus de capital, lo que torna comprensible que sea más importante en los Estados Unidos la presencia de ese régimen de tenencia.

Estos indicadores, si bien poco elaborados, permiten retener algunas ideas centrales sobre las que es necesario profundizar. En primer lugar, existe una marcada diferencia entre Brasil y México en la estructura de la distribución de la tierra en cuanto al número, superficie y tenencia de las propiedades, lo que implica diferencias también en la forma en que se relacionan y se integran los agentes en el proceso social de producción en el sector agrícola de ambos países.

Por último, con el propósito de apreciar en qué condiciones el trabajador agrícola enfrenta la naturaleza y para tener una idea del esfuerzo que debe desarrollar para obtener la producción, se presenta un indicador expresado por la relación entre número de trabajadores agrícolas y número de tractores disponible para el proceso productivo (véase el cuadro 7).

El significado de estas cifras es clave para indicar el grado de diferencia que existe entre las condiciones materiales de producción en los tres países; además, es sugerente para comprender las magnitudes de las transformaciones materiales que acompañan o deben dar base a los cambios estructurales de población.

Cuadro 7

TRABA JADORES AGRícolas POR TRACTOR

\begin{tabular}{|c|c|c|c|c|}
\hline & & $\begin{array}{l}\text { Brasil } \\
\text { (1970) }\end{array}$ & $\begin{array}{l}\text { Mextco } \\
(1970)\end{array}$ & $\begin{array}{r}\text { Estados } \\
\text { Unidos } \\
(1970)\end{array}$ \\
\hline I & $\begin{array}{l}\text { Población econbmicanente } \\
\text { activa azrícola (miles) }\end{array}$ & 13071.4 & 5283.7 & 2840.5 \\
\hline II & Frimero de tractores (miles) & 157.3 & $\$ 15.2$ & $4619.0^{2 /}$ \\
\hline$I / I I$ & & 83.1 & 45.9 & 0.6 \\
\hline
\end{tabular}

Fuente: Población económicamente activa de Brasil y México: Censos de pobla ción; Número de tractores: Brasil: Sinópse Preliminar do Censo Agropecuarıo IBGE, Río de Janeiro, 1973. p. 22. México: Datos básicos. $V$ Censo agrícolaganadero y ejidal, 1970, México, Dirección General de Estadística, 1973, p. 56. Estados Unidos: Statistical Abstract of the United States, 1973, p. 600 (dato referido a 1969).

a Referido a 1969. 


\section{Cuadros básicos de la estructura de población}

A continuación se presentan algunas estadísticas básicas de Brasil y México referentes al crecimiento y composición de la población entre 1940 y 1970.

En los cuadros 8 y 9 aparece información en cuanto a la población total, urbana y rural y sus respectivas tasas de crecimiento.

Como puede verse, Brasil tiene alrededor del doble de la población mexicana. Esa proporción, que se mantiene de 1940 a 1970, experimenta una leve tendencia a disminuir, dado que en Brasil la tasa de crecimiento total ha sufrido una leve pero persistente baja en el período señalado, en tanto que en México prácticamente se mantiene constante. Esta cir-

\section{Cuadro 8}

BRASIL: Población URbaNa Y RURAL Y EN localidades SEgúN NúMERo DE HABITANTES, 1940-1970

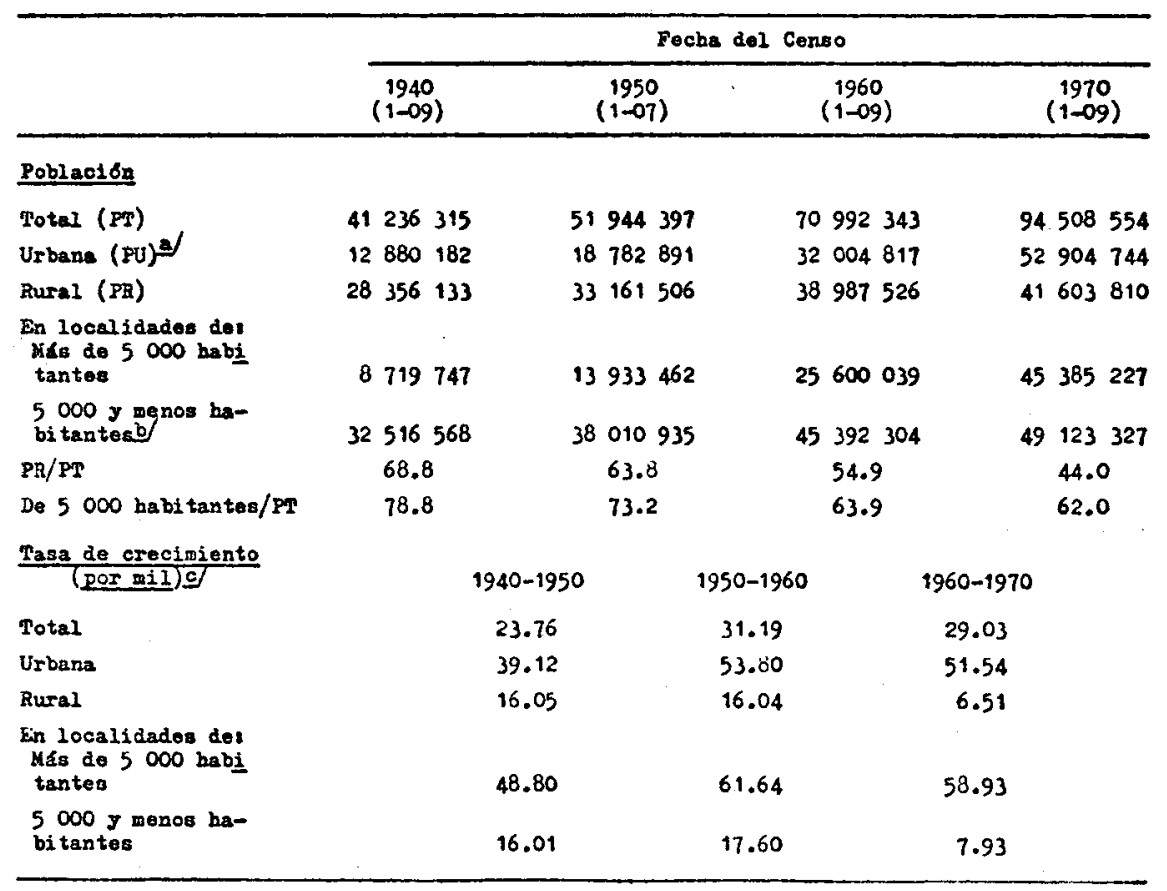

Fuente: Brasil, Sinópse Preliminar do Censo Demografico, 1970; "Informe de población por zonas para 1940-1950-1960 y 1970", cuadro 5, p. 87; "Población en localidades de...", cuadro 4, p. 39 (1950-1960-1970) y; Censo de población, 1950, "Informe 1940", cuadros X y XI, pp. 274-276.

a La población urbana incluye la suburbana (población censal).

b La población rural más la población de ciudades y villas de menos de 5000 habitantes.

c Las tasas de crecimiento se calcularon de acuerdo con la fórmula $\mathrm{Pt}=\mathrm{Po}(1+\mathrm{r})^{\mathrm{t}}$. 
Cuadro 9

México: Población uRbana y RURAL EN localidades SEgúN NÚMERO DE HABITANTES, 1940-1970

\begin{tabular}{|c|c|c|c|c|c|c|c|c|}
\hline \multirow[b]{2}{*}{ Poblacion } & & $\begin{array}{r}1940 \\
(6-03) \\
\end{array}$ & & $\begin{array}{c}1950 \\
(6-06)\end{array}$ & & $\begin{array}{r}1960 \\
(8-06) \\
\end{array}$ & \multicolumn{2}{|r|}{$\begin{array}{c}1970 \\
(28-01)\end{array}$} \\
\hline & & & & & & & & \\
\hline Total (PT) & & 19653552 & 25 & $25 \quad 791017$ & & 34923129. & 48 & $3.377 \quad 363$ \\
\hline Uxbana (PU) & & 6896111 & & 10983483 & 17 & 17705118 & 28 & $329 \cdot 319$ \\
\hline Eural (PR) & & 12757441 & & 14807534 & 17 & 7218011 & 20 & 048044 \\
\hline $\begin{array}{l}\text { En localidades del } \\
5 \text { o00 y mas habi- } \\
\text { tantes }\end{array}$ & &, 5.420000 & $\cdots$ & 8937251 & 14 & 14745658 & 24 & 200163 \\
\hline $\begin{array}{l}\text { Menos de } 5000 \text { ha } \\
\text { bitanteb }\end{array}$ & & 14233552 & & 16853766 & & 0177471 & 24 & +177200 \\
\hline $\mathrm{FR} / \mathrm{PT}$ & & 64.9 & & 57.4 & & 49.3 & & 41.4 \\
\hline 5000 habi tantes/PP & & 72.4 & & 65.3 & & 57.8 & & 50.0 \\
\hline$\frac{\text { Tana de crecimiento }}{(\text { por mil) } a}$ & & & $1940-1950$ & & $1950-1960$ & & $1960-1970$ & \\
\hline Total & & ○ & 26.90 & & 30.78 & & 34.38 & \\
\hline Urbana & & & 46.50 & & 48.90 & & 49.97 & \\
\hline Bural & : & & 14.65 & & 15.20 & & 15.91 & \\
\hline $\begin{array}{l}\text { En localidades del } \\
5 \text { o00 y wás babi- } \\
\text { tantes }\end{array}$ & & & 50.05 & & 51.35 & & 52.74 & $\therefore$ \\
\hline $\begin{array}{l}\text { Kenos de } 5000 \text { ha } \\
\text { bitantes }\end{array}$ & & & 16.64 & & 18.16 & & 18.93 & $\therefore$ \\
\hline
\end{tabular}

Fuente: México, Censo de población, 1960, Resumen general, "Población por zonas", censos de 1940, 1950 y 1960", cuadro 1, p. 1; Censo de población, 1970, Resumen de las principales características por entidades federativas, p. XVII; 1940: Dinámica de la población de México, El Colegio de México, 1970, cuadro V-10, p. 131; 1950: Censo de población. Resumen general, cuadro 26-A, p. 119; 1960: Censo de población. Resumen general, cuadro 5, p. 59.

a Las tasas de crecimiento se calcularon de acuerdo con la fórmula $\mathrm{Pt}=\mathrm{Po}(1+\mathrm{r})^{\mathrm{t}}$.

cunstancia se debe a que la tasa de crecimiento de la población mexicana está determinada de manera básica por una tasa de natalidad mayor, no tanto por diferencias en las tasas de mortalidad (véase el cuadro 10).

Destaca también la elevada tasa de crecimiento total que registran ambos países, lo cual se debe al mantenimiento de altas tasas de natalidad junto con tasas de mortalidad bajas y decrecientes. ${ }^{2}$

Veamos ahora la distribución de la población urbana y rural. En

2 Se podría concluir, por los niveles observados, que si las tasas de mortalidad están ya a niveles muy bajos, serán poco significativos los incrementos en los ritmos de crecimiento de la población, debidos a este factor en ambos países. Es de esperarse una continua, aunque no rápida, disminución en la tasa de crecimiento por efectos de baja en las tasas de natalidad, tendencia ésta que se ha manifestado en forma regular en los últimos 30 años. 
Cuadro 10

TASAS DE NATALIDAD Y MORTALIDAD

(por mil)

\begin{tabular}{|c|c|c|c|c|}
\hline & \multicolumn{2}{|c|}{ Natalidad } & \multicolumn{2}{|c|}{ Borta\}2dad } \\
\hline & Brasil & Mexico & Brasil & México \\
\hline $1940-1950$ & 42.0 & 47.3 & 17.4 & 19.5 \\
\hline $1350-1960$ & 40.5 & 45.6 & 11.8 & 13.5 \\
\hline $1960-1970$ & 36.0 & 44.7 & 10.1 & 9.6 \\
\hline
\end{tabular}

Fuente: CELADE, Crecimiento urbano de siete paises de América Latina. Tendencias en el período 1940-1970 y perspectivas para 1980, Parte II, Anexo A, 1973.

primer lugar, es necesario señalar que los criterios oficiales de ambos países son distintos en cuanto a la definición de población urbana. En México se considera población rural a la que habita en localidades con población menor a 2500 habitantes. En Brasil, población rural es la no ubicada en los perímetros urbanos y áreas suburbanas. El perímetro urbano y el área suburbana son determinados a nivel de las unidades administrativas menores que son los municipios en los cuales se subdivide la población en: urbana, suburbana y rural. De manera preliminar se considera a la población rural del país como aquella no clasificada como urbana y suburbana en los censos de población.

Las poblaciones rurales de Brasil y México son entonces de partida, según los criterios censales, no comparables. En un intento por definir un corte común para los dos países, se analizan las estadísticas disponibles sobre la distribución nacional de las poblaciones según tamaño de las localidades. El límite común inferior que se consiguió fue de 5000 habitantes. ${ }^{3}$

3 Como se sabe, existe desde hace mucho un largo debate, y hasta hoy poco acuerdo final, sobre cuáles serían los criterios para definir si un determinado conglomerado debe o no ser clasificado como urbano. En lo referente al llamado criterio ecológico-demográfico, las proposiciones más corrientes oscilan entre 2000 y 20000 habitantes. Consideremos que en países como México y Brasil, por sus características sociales y económicas, se podría admitir que un conglomerado de 2000 habitantes no es rural, porque existe ya en su interior una organización, un proceso de división social del trabajo que rompe los trazos de aislamiento propio del modo de vida campesino. Pero como ya se dijo, si el debate persiste, mucho habría que ampliarlo, de manera principal en los dos países que se analizan, para presentar argumentos con suficiente evidencia que justifique tal decisión. Además, el único nivel en los datos disponibles, común para los dos países por tamaño de localidades, es 5000 habitantes; de allí que lo adoptemos para efectos de análisis. En el trabajo de Luis Unikel, "Ensayo sobre una nueva clasificación de la población rural y urbana en México", Demografía y Economía, Vol. II, Núm. 1, El Colegio de México, 1968, se presenta el problema de referencia acompañado de un análisis para México. 
En los cuadros 8 y 9 se presentan los volúmenes de población urbana y rural de ambos países entre 1940 y 1970 de acuerdo con los dos criterios mencionados, o sea el censal y con el corte a nivel de aglomerados de 5000 habitantes. Como se puede apreciar, existen diferencias bastante signficativas; de acuerdo con el criterio censal se subestima la población rural brasileña, comparativamente con la mexicana, hasta 1950 y después de esta fecha se sobrestima.

Veamos ahora los datos sobre la población económicamente activa (PEA). Llama la atención a primera vista el agudo contraste entre el comportamiento de la población total, tanto el de la urbana como la rural, en los dos países y el comportamiento de la PEA en cuanto a su crecimiento. Para la población total hay una similitud de comportamiento en cuanto a que la PEA presenta diferencias significativas y contrastes muy acentuados.

\section{Cuadro 11}

Población ECONÓMICAMENTE ACTIVA (PEA), 1940-1970

\begin{tabular}{|c|c|c|c|c|c|}
\hline \multirow{2}{*}{ Poblacion } & \multicolumn{5}{|c|}{ Peche dol Censo } \\
\hline & $\begin{array}{c}1940 \\
(I-09)\end{array}$ & $\begin{array}{c}1950 \\
(I-07)\end{array}$ & & $\begin{array}{c}1960 \\
(I-\infty)\end{array}$ & $\begin{array}{c}1970 \\
(I-09)\end{array}$ \\
\hline \multicolumn{6}{|l|}{ Brasil } \\
\hline PEA Total & 15317192 & 17336000 & & 2651263 & 29557224 \\
\hline PEA Urbana & 5473120 & 6966094 & $=$ & & 16485839 \\
\hline PEA Rural 9 & 9844072 & 10369906 & & & 13071385 \\
\hline PEA Rural/PEA Total & 64.3 & 59.8 & & & 44.2 \\
\hline Tesa de crecimiento & \multirow{2}{*}{\multicolumn{2}{|c|}{$1940-1950$}} & \multirow{2}{*}{\multicolumn{2}{|c|}{$1950-1960$}} & \\
\hline ( $\operatorname{Ror} \operatorname{ail})$ & & & & & $1950-1970$ \\
\hline PEA Total & \multicolumn{2}{|c|}{12.67} & \multicolumn{2}{|l|}{26.65} & 26.97 \\
\hline PEA Urbana & \multicolumn{2}{|c|}{24.84} & & & \\
\hline PWL Eural & \multicolumn{2}{|c|}{5.31} & & & \\
\hline Ydxico & $(6-03)$ & $(6-06)$ & & $(8-\infty)$ & $(28-01)$ \\
\hline PEA Total & 5677086 & 8272093 & & 1253297 & 12994392 \\
\hline PEA Drbane & 1739509 & 3351049 & & 4966566 & 7710698 \\
\hline PEA Rural & 3937577 & 4921044 & & 6286731 & 5283694 \\
\hline PEA Rural/PEA Total & 69.4 & 59.4 & 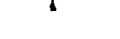 & 55.9 & 40.7 \\
\hline \multicolumn{6}{|l|}{ Tasa de crecimiento } \\
\hline (pormil) & \multicolumn{2}{|c|}{$1940-1950$} & \multicolumn{2}{|l|}{$1950-1960$} & $1960-1970$ \\
\hline PEA Total & \multicolumn{2}{|c|}{37.44} & \multicolumn{2}{|l|}{31.26} & 15.04 \\
\hline PEA Urbana & \multicolumn{2}{|c|}{66.12} & \multicolumn{2}{|l|}{40.13} & 46.69 \\
\hline PEA Rural & \multicolumn{2}{|c|}{22.01} & \multicolumn{2}{|l|}{24.79} & -17.87 \\
\hline
\end{tabular}

Fuente: Brasil: Tabulaçoes Avançadas do Censo Demográfico de 1970, cuadro V, IBGE, 1971. México: Resumen general del censo de población: Dirección General de Estadística, 1940: cuadro 1; 1950: cuadro 10; 1960: cuadro 25; 1970: IX; Censo general de población. Resumen de las principales características por entidad federativa, México, noviembre de 1970.

a En la PEA rural se considera para efectos de comparación: agricultura, silvicultura, caza y pesca e industrias extractivas (vegetal y mineral). 
Cuadro 12

Población eConómicamente activa (PEA) POR zona y seXo según fechas censales (miles de personas)

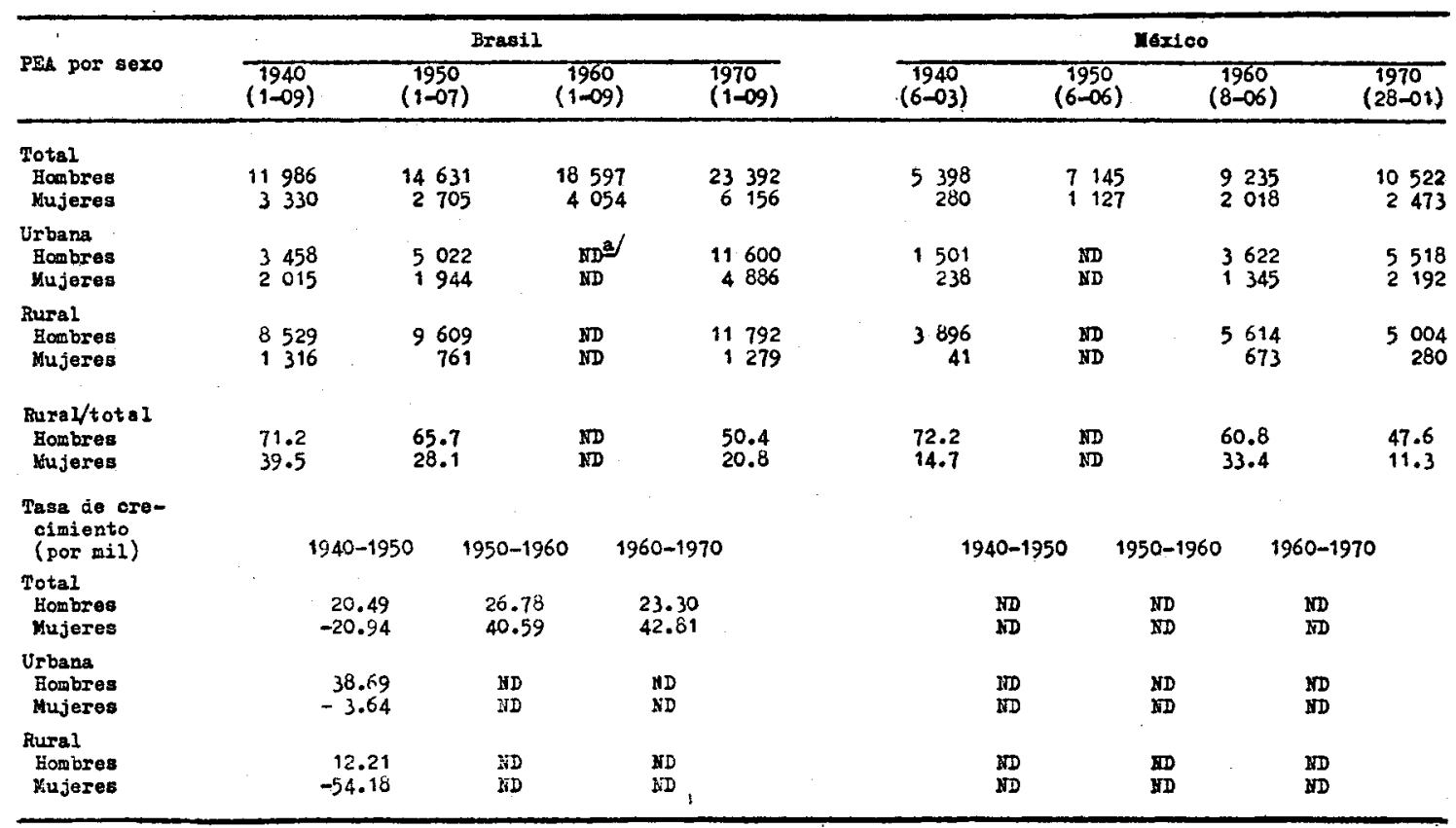

Fuente: Brasil: Las mismas fuentes mencionadas para el cuadro 11. México: Las mismas fuentes mencionadas para el cuadro 11 y Demographic Yearbook 1956, Naciones Unidas, cuadro 11, p. 317 para datos

a ND: Cifras no disponibles. 
En los cuadros 11 y 12 se observa entre 1940 y 1950 que la tasa de crecimiento de la PEA en México, al principio más del doble de la del Brasil, se aproxima bastante en 1950-1960; y la tasa de crecimiento de la PEA en el Brasil pasa a ser prácticamente el dobla de la mexicana en el período 1960-1970, o sea una reversión completa de los ritmos de crecimiento en el corto período de 30 años.

A las diferencias entre el comportamiento de las tasas de crecimiento de la PEA, se agregan las diferencias en términos sectoriales o sea urbano y rural. La tasa de crecimiento de la PEA urbana entre 1940 y 1970 se mantiene elevada y creciente en Brasil en tanto que en México registra un elevado crecimiento, aunque irregular. Las diferencias principales se observan en el crecimiento de la PEA rural, para la cual en los dos paises se registra una baja muy acentuada en el período 1960-1970, hasta registrar un crecimiento negativo en México al disminuir en valor absoluto la PEA en 1970, en relación a la de 1960. Al considerarse por sexo y por sector, las diferencias son cada vez más amplias, con ritmos de crecimiento de la PEA muy "irregulares".

Estas expresiones del crecimiento de la población total y de la PEA en los dos países significó fuertes cambios en las tasas de actividad, de manera principal en el sector rural (véase el cuadro 13).

Nuestro objetivo es, como se dijo antes, profundizar en el análisis del sector rural para intentar "explicar" los fenómenos registrados. Es posible que algunos comportamientos "raros" de la dinámica de pobla-

\section{Cuadro 13}

TASAS BRUTAS DE ACTIVIDAD, a POR SEXo, zonas URBANA Y RURAL, EN EL PERÍ́Do 1940-1970

\begin{tabular}{|c|c|c|c|c|c|c|c|c|}
\hline & \multicolumn{2}{|c|}{1940} & \multicolumn{2}{|c|}{1950} & \multicolumn{2}{|c|}{1960} & \multicolumn{2}{|c|}{1970} \\
\hline & Brasil & Hérico & Brasil & MExico & Brasil & Héxico & Brasil & Kéx 2 co \\
\hline Total & 37.14 & 28.89 & 33.37 & 32.07 & 32.30 & 32.22 & 31.70 & 26.86 \\
\hline $\begin{array}{l}\text { Hombres } \\
\text { Mujeres }\end{array}$ & $\begin{array}{l}58.15 \\
16.15\end{array}$ & $\begin{array}{r}55.67 \\
2.80\end{array}$ & $\begin{array}{l}56.52 \\
10.38\end{array}$ & $\begin{array}{r}56.28 \\
8.61\end{array}$ & $\begin{array}{l}53.12 \\
11.55\end{array}$ & $\begin{array}{l}53.03 \\
11.52\end{array}$ & $\begin{array}{l}50.49 \\
13.15\end{array}$ & $\begin{array}{l}43.72 \\
10.23\end{array}$ \\
\hline Urbane & $(57.72)$ & $(32,10)$ & $(49.26)$ & $(37.50)$ & $(40.97)$ & $(33.69)$ & $(36.30)$ & $(31.87)$ \\
\hline Total & 39.08 & 25.23 & 36.54 & 30.51 & 32.77 & 28.06 & 31.14 & 27.22 \\
\hline $\begin{array}{l}\text { Hombres } \\
\text { Hujeres }\end{array}$ & $\begin{array}{l}57.49 \\
22.18\end{array}$ & $\begin{array}{r}46.34 \\
6.52\end{array}$ & $\begin{array}{l}57.01 \\
17.83\end{array}$ & & & $\begin{array}{l}42.09 \\
14.79\end{array}$ & $\begin{array}{l}45.98 \\
18.16\end{array}$ & $\begin{array}{l}39.65 \\
15.22\end{array}$ \\
\hline Rural & $(29.21)$ & (23.37) & $(26.98)$ & $(29.20)$ & $(26.60)$ & $(31.16)$ & $(26.61)$ & $(21.86)$ \\
\hline Total & 34.40 & 30.87 & 30.93 & 33.24 & 31.20 & 36.52 & 31.42 & 26.36 \\
\hline $\begin{array}{l}\text { Honbres } \\
\text { Mujeres }\end{array}$ & $\begin{array}{r}58.24 \\
9.43\end{array}$ & $\begin{array}{r}60.36 \\
0.66\end{array}$ & $\begin{array}{r}56.15 \\
4.67\end{array}$ & & & $\begin{array}{r}63.72 \\
8.01\end{array}$ & $\begin{array}{r}55.03 \\
6.42\end{array}$ & $\begin{array}{r}48.95 \\
2.86\end{array}$ \\
\hline
\end{tabular}

Fuente: Brasil y México: Datos elaborados a partir de los cuadros 8, 9, 11 y 12. a En el cuadro aparecen dos estimaciones de tasa de actividad para el total de la zona urbana y rural, los totales se calcularon con la definición censal, y los que aparecen entre paréntesis los que resultan al considerar el tamaño de las localidades, según tuvieran más o menos de cinco mil habitantes. 
ción sean sólo fruto de errores en los registros censales. Sólo a partir de un análisis económico-demográfico, en el que se combinen principalmente los registros censales de población con un amplio conjunto de informaciones de los censos económicos y de otras fuentes, se podrá avanzar en el conocimento de la dinámica de población de ambos países y observar los hechos reales bajo una perspectiva correcta.

\section{El MARCo TEÓRICO}

El análisis del crecimiento de la población rural y la dinámica de transferencia de la fuerza de trabajo (FT) del campo a la ciudad, son temas de fundamental importancia dentro del estudio de las sociedades, en especial de aquéllas en donde el gran contigente de población existente en los sectores rurales hacen que éstos participen de manera significativa en la determinación de los niveles de crecimiento de la población nacional, de la estructura de empleo y, por consiguiente, de toda la estructura social.

Ahora bien, el estudio de la población rural, si no se desea sólo exponer algunas cifras censales en cuanto a volumen y composición por sexo y edad de esa población, sino penetrar además en su dinámica para comprender el porqué de los perfiles que se observan, exige la complementación de informaciones a partir de diversos campos de conocimiento, del complejo conjunto de relaciones causales que actúan en forma directa en la determinación de los niveles de crecimiento y del desplazamiento del hombre.

Para conocer e intentar explicar lo que acontece con la población rural, es necesario entender lo que sucede en especial en la agricultura (considerada como expresión de todas las actividades económicas que se desarrollan en el campo).

Por supuesto que existe una interdependencia muy grande entre la economía agrícola y la urbana y entre la dinámica de población de ambos sectores, por lo que es estrictamente necesario hacer un análisis del sector urbano para captar parte de la explicación de lo que ocurre en el campo. Aquí se enfoca de manera especial el sector rural y se profundiza en el análisis de las relaciones económicas, en un intento por comprender su dinámica $\mathrm{y}$, de manera complementaria, se consideran los fenómenos urbanos al introducir referencias o vinculaciones que conforman el funcionamiento integrado del sistema campo-ciudad.

Ahora bien, así como en la ciudad los niveles de empleo de la fuerza de trabajo están asociados de modo directo con los niveles de acumulación de capital y los moldes tecnológicos empleados en sus diversas esferas de producción y de circulación, al mismo tiempo que el sistema de precios refleja la dinámica económica y orienta las decisiones del capitalista individual, en las actividades agrícolas sucede algo semejante. Pero se considera que además de los indicadores clásicos del análisis 
económico, habría que señalar el interés en estudiar un factor clave en el sector rural: la tenencia de la tierra.

El concepto de tenencia comprende la relación de propiedad existente en el campo, o sea "la distribución de los derechos de propiedad y del usufructo de la tierra y de las aguas entre personas o grupos de una sociedad".4

La razón del interés en ese aspecto se deriva del hecho de que en cualquier análisis del comportamiento del hombre, es básico el estudio de las relaciones de propiedad. En el campo, este aspecto es de importancia fundamental, en especial en las economías de menor desarrollo relativo. En el campo, como la monetarización no cubre muchas etapas de los procesos de producción y de circulación, sucede que los análisis de valores expresados en términos monetarios son muy limitados, dejan fuera de consideración gran parte de los procesos económicos reales.

En esas condiciones, es de esperarse que el análisis de la tenencia de la tierra es significativo para explicar la dinámica de la población rural, pues como lo señala Barraclough "...Donde hay poco desarrollo técnico, la tierra (y el consiguiente control de la mano de obra) es la fuente principal de la riqueza. Como resultado, el control sobre la tierra determina en gran parte la distribución de la riqueza en las zonas agrícolas atrasadas técnicamente. Pero no se pueden obtener rentas de la tierra sin trabajo. Por lo tanto, el modelo de distribución de los derechos de propiedad está necesariamente acompañado por un sistema de relaciones interpersonales e intergrupos que gobiernan la aplicación del trabajo a la tierra".

En cuanto a la expansión de ambos sectores, se acepta que como tendencia general el desarrollo de las sociedades conduce a una forma urbana de organización social. Esto implica un continuo flujo de población rural a las ciudades y la mayor expansión de las actividades no agrícolas.

La explicación básica de esa tendencia radica en que la forma urbana de organización social es potencialmente superior a la rural pues la concentración del capital es condición necesaria para el desarrollo moderno al ser esa concentración económicamente más "eficiente" en la ciudad, en la medida en que permite que el capitalista obtenga y mantenga elevados niveles de ganancia a través del ahorro en los gastos de transporte y de comunicaciones, lo que posibilita una mayor velocidad de rotación del capital así como el disfrute de las economías externas y de escala dentro de un cuadro mucho más diversificado de oportunidades de inversión.

En una primera aproximación, se podría decir que las características básicas de la agricultura en los países de menor desarrollo relativo son:

4 Solon L. Barraclough, Notas sobre la tenencia de la tierra, ICIRA, Santiago de Chile, 1970, p. 62.

5 Barraclough, op. cit., p. 52. 
a) Elevada proporción del producto agrícola (PA) en el producto nacional (PN);

b) Elevada proporción de la fuerza de trabajo agrícola (FTA) en la fuerza de trabajo nacional (FTN);

c) Relación FTA-FTN mayor que PA-PN.

Ahora bien, como ya se señaló, por el hecho de no ser economías "desarrolladas capitalísticamente", los instrumentos clásicos de la economía de mercado - sistema de precios y salarios- no "operan", o lo hacen con mucha menor eficacia que en el sector urbano. En estas condiciones el análisis debe considerar otros elementos con un enfoque más ajustado, por lo menos en principio, a la realidad que se quiere analizar.

De acuerdo con esta preocupación, se analiza la actividad agrícola en Brasil y México, dividida en tres subsectores básicos:

I. Subsector rural de mercado exterior (SRME)

II. Subsector rural de mercado interno (SRMI)

III. Subsector rural de subsistencia (SRSB)

En el sector rural (SR) la penetración de relaciones capitalistas serían más rápidas e intensas primero en el caso I, menor en el II y casi nula en el III.

Cada uno de esos subsectores operan bajo características tecnológicas específicas y mantienen vínculos especiales con el sector urbano.

\section{El funcionamiento de los subsectores}

El subsector de mercado externo por tradición ha constituido la vanguardia del desarrollo agrícola y durante mucho tiempo fue el más dinámico en los países considerados. Las relaciones capitalistas de producción se han manifestado de forma más patente en este subsector.

Debe señalarse que en América Latina, aun en el período en que el trabajo esclavo fue la base principal de las economías, el SRME, por la naturaleza de sus relaciones con los centros metropolitanos, se constituye en el centro del proceso de innovaciones tecnológicas y en el "peso" para la determinación de las estructuras económicas y sociales que se formaban en el interior de las economías.

En nuestro análisis, al considerar como elemento central el estudio de fenómenos en los últimos decenios, sólo de paso vamos a procurar comentar los vínculos internos existentes entre los diversos sectores y subsectores en el pasado más remoto. Naturalmente, en los países objeto de nuestra investigación, el SRME siempre fue dependiente en alto grado de los ciclos económicos de las metrópolis durante el período colonial y aun después de la independencia, e inclusive hasta fecha reciente con- 
tinúa la dependencia de algunos pocos países que han tenido la hegemonía del proceso de acumulación de capital. Ahora bien, lo que ha cambiado es el nivel de la dependencia de los otros sectores y subsectores internos en relación a sus respectivos SRME.

Veamos con alguna aproximación lo que acontecía en las etapas ascendentes de los ciclos económicos en las metrópolis: el SRME absorbe una mayor cantidad de tierras y mano de obra. Esa tierra y mano de obra adicional son retiradas de los SRMI y SRSB. En las fases iniciales puede haber tierra sin ningún uso y por lo tanto ésta puede ser apropiada por el SRME sin afectar en nada a otros sectores. Si bien, por ló general siempre hubo poblaciones que se consideraban propietarias de las tierras, de manera principal de aquellas que despertaban el interés inmediato de los conquistadores y colonizadores. Pero se puede decir que el factor condicionante básico en los primeros siglos es la fuerza de trabajo (FT) que orienta la evolución tecnológica en el sentido de intensificar o no la utilización de nuevos equipos. Cabe reforzar entre tanto de nuevo la idea de que el factor tierra no fue en estricto sentido neutral. Desde el punto de vista de definición de los perfiles generales de la naturaleza de las actividades que se desarrollaban en cada región, el factor tierra influyó en la medida en que eran unos pocos productos los que tenían posibilidad de integrarse al comercio de las metrópolis. La adecuación de las tierras estaba muy lejos de ser homogénea para esos productos en los diversos países y dentro de ellos, en las diversas regiones. Es así que en el cultivo de la caña de azúcar se utilizaba una tecnología muy distinta de la extracción mineral, o del cultivo de tabaco, o del cacao o de la extracción de maderas, para señalar sólo algunos productos de exportación que fueron importantes en América Latina en el período colonial. La organización de la producción de uno y otro de esos productos no está condicionada sólo por la disponibilidad de mano de obra, sino también por el clima y el suelo.

Ahora bien, implantado a través de las relaciones con la metrópoli un SRME, empieza a desarrollarse (si es que no existiera ya antes) un SRMI concomitante con el sector urbano.

E1 desarrollo del SRME de suyo lleva implícito un sector urbano para todas las actividades relacionadas con la exportación y la importación de productos manufacturados de la metrópoli. Esto último a su vez también implica un SRMI para abastecer a la población urbana.

El SRSB proporciona tierras y mano de obra para SRME y SRMI, así como algunos excedentes eventuales de sus productos; pero en esencia constituye área de expansión susceptible de ser conquistada y destruida por el avance de los otros subsectores.

En los períodos críticos del SRME, provocados por lo general por las crisis en las metrópolis o por el surgimiento de competidores más eficientes, la crisis se expande en lo interno a través del SRMI y el sector urbano. El SRSB es el único que no se ve afectado por la recesión. 
Existen algunas opiniones en cuanto a que la población afectada por la crísis retorna a actividades de subsistencia, sin embargo, consideramos que esto es poco probable. Lo que debe ocurrir es una reducción importante en los niveles de ingreso en el SRME, SRMI, y en el sector urbano, y un aumento muy grande de los niveles de desempleo y mortalidad, sin retroceso a actividades de subsistencia. Puede haber, sí, un flujo grande de personas que circulan del SRME y del SRMI al sector urbano con lo que terminan sus años de vida activa de manera rápida en esa dislocación sin futuro. La rapidez con que se recupera el SRME condiciona la posibilidad de que la población errante pueda encontrar empleo para su fuerza de trabajo. ${ }^{6}$

En conclusión, el motor del proceso de acumulación para la economía en tal período es el SRME. Su ritmo de expansión determina el ritmo de expansión del SRMI y del sector urbano y el ritmo de destrucción del SRSB.

En algunos de los esquemas más conocidos de modelos de crecimiento económico, en donde se consideran las relaciones campo-ciudad, las vinculaciones entre el sector rural y el urbano se darían en términos generales de la siguiente forma: el sector rural proporciona alimentos y mano de obra al sector urbano dado que la productividad marginal del trabajo en el primero es nula o casi nula y la transferencia de fuerza de trabajo puede hacerse sin comprometer los niveles de producción en el sector rural. Éste produce alimentos que en parte son transferidos al sector urbano para atender las necesidades de la población urbana, otra parte queda para la propia población rural y para mantener los niveles de producción. Pero también el sector rural produce excedentes de los cuales parte se transfiera al urbano para alimentar la población que se transfiere del primero al segundo y parte se destina a reinversión en el

6 En verdad pueden operar fuerzas que retengan la población en las regiones o en la misma unidad de producción. Asi, al existir tierras desocupadas o subocupadas previamente o por efecto de la crisis, puede que se permita o se estimule a la fuerza de trabajo que llegue a estar desempleada en el SRME para que permanezca en actividades propias de subsistencia. Esto tiene la ventaja de que esa fuerza de trabajo queda disponible para ser empleada cuando se supera la crisis en el SRME. Además, hay que considerar que con frecuencia los trabajadores son deudores en función de los sistemas de abastecimiento que operan en las grandes unidades de producción agrícola. De esta forma, la permanencia de los trabajadores en el área facilita el control y aumenta las posibilidades de cobro de las deudas pendientes. En síntesis, en la medida en que la permanencia de trabajadores en la región pueda ser realizada con la ocupación de tierras en actividades que no comprometan la rentabilidad de la unidad y, además, que no amenacen la naturaleza misma del sistema de tenencia de la tierra, puede ocurrir temporalmente una ampliación de las actividades de subsistencia. Consideramos entre tanto que lo más frecuente es el desplazamiento de la población de la unidad de producción, debido a las dificultades que existen para mantenerse en relaciones de producción menos desarrolladas. Por lo tanto, a la larga, las crisis en el SRME 7 funcionan como elemento de expulsión de la fuerza de trabajo del campo a la
ciudad. 
rural, lo que permite elevar los niveles de producción para atender los incrementos de demanda, cada vez mayores, del sector urbano. Este proceso en los modelos mencionados adquiere carácter regular y gradual, ajustándose a los impulsos originados en el sector urbano.

Los rasgos mencionados se ajustan más a lo que serían las relaciones entre el SRMI y el sector urbano en nuestra formulación; pero allí también existen diferencias importantes. Para nosotros, la fuerza de trabajo del SRMI es de productividad marginal baja, pero está lejos de ser nula o casi nula. Por el contrario, en el SRSB existiría una situación de productividad marginal nula o casi nula, pero no es el SRSB el que proporciona alimentos al sector urbano.

En nuestro esquema las relaciones no son armónicas y lineales. $\mathrm{Al}$ contrario, las vinculaciones entre los sectores y subsectores están lejos de ser reguläres. Es un todo que se desarrolla a base de movimientos conflictivos. Así, no se debe confundir y unir el SRSB con otros subsectores; en éste existen regularidades muy particulares que exigen un análisis detallado y específico. El avance del SRME, del SRMI y del sector urbano se realiza no con una integración del SRSB y sí con su "destrucción". Esa destrucción es más una destrucción de "relaciones" de producción que de otros medios materiales, si bien la destrucción de bienes y personas no sea extraña a la penetración y a la conquista de las llamadas fronteras económicas internas, aun en los días actuales. Ocurre esto como una apropiación, por los otros subsectores y sectores, de riqueza previamente no transformada en mercancía, o sea no integrada a la producción mercantil. Esa apropiación se hace tanto de productos como de fuerza de trabajo; es una apropiación de características primitivas en los términos de Marx y significa incorporación a la acumulación de importantes volúmenes de riqueza.

Además, hay que considerar que el SRMI constituye también una importante fuente de acumulación en la medida en que es subsidiario tanto del sector urbano como del SRME. Además, al inicio, el SRME y después el sector urbano detentan el "poder", fijan las reglas del "juego" y extraen, ya sea por el sistema de precios o por otras formas menos sutiles, importantes volúmenes de valor creado en SRSB y SRMI sin que los cambios operen en términos de valores equivalentes.

Con frecuencia el SRMI está integrado a las mismas unidades de producción del SRME en los grandes latifundios, en total dependencia, inclusive física. Otras veces parte del SRMI se ubica cerca de las grandes ciudades en los llamados "cinturones verdes". Allí disfrutan de mejores condiciones y pueden inclusive disponer de altos ingresos, pero también la expansión de las ciudades los va eliminando poco a poco, o alejando a tierras menos productivas. Las mejores tierras para las actividades propias de los cinturones (verduras, legumbres) son también las tierras codiciadas por la especulación inmobiliaria.

Es claro que el proceso de expansión de las ciudades valoriza las tie- 
rras y hace que los propietarios agrícolas se beneficien de la valorización, pero casi siempre son los especuladores inmobiliarios los que se llevan la mejor tajada, ya que por anticipado, en los momentos oportunos, se apropian de las tierras a bajo precio.

Esta forma de operar conduce a que por lo general el SRMI funcione casi a nivel de subsistencia, con un proceso de acumulación reducida. El SRME es el subsector dinámico e innovador en tales circunstancias, con elevadas ganancias y acelerado proceso de acumulación, pero expuesto a las vicisitudes del mercado internacional.

El SRMI opera con niveles bajos de ganancia, un proceso de acumulación que se ve limitado por la expropiación que le hace el SRME, por una parte, y el sector urbano por otra. Dentro del SRMI, lo relacionado de manera más directa con la ciudad, es más dinámico, recibe mayores estímulos y dispone de mayor poder de negociación, lo que le permite acelerar el proceso interno de acumulación a pesar de estar, en última instancia, dominado por el sector urbano. Esta ventaja tiene la contra-' partida de estar expuesto a la pérdida de su espacio vital por la expansión del uso urbano del suelo.

Con relación al SRMI, cabe todavía una ampliación de las consideraciones sobre algunas de sus características. Como ya se mencionó, este sector se relaciona tanto con el sector urbano como con el SRME a través del abastecimiento de alimentos y materias primas. Pero las relaciones que se manifiestan no son por necesidad idénticas en ambos casos. En primer lugar, la producción de materias primas en el SRMI se hace casi de manera exclusiva para el sector urbano y las relaciones que se establecen entre ambos son más "equilibradas". Esto es, hay un nivel menor de explotación del SRMI por parte del sector urbano que el que ejerce el SRME sobre el SRMI, puesto que las actividades de exportación se efectúan en grandes unidades de producción, que ejercen en su área de influencia un dominio mucho más intenso y monopolizador. Por el contrario, las relaciones entre el sector urbano y el SRMI se realizan bajo condiciones menos desventajosas para este último, pues éste se enfrenta con un poder comprador menos concentrado en términos de agentes involucrados.

Uno de los resultados más importantes de esas diferentes situaciones, es que las relaciones entre el SRMI y el SRME tienden a generar minifundios en el SRMI, o sea pequeñas unidades de producción dedicadas en esencia a la producción de alimentos, con un intenso proceso de explotación y en donde por lo general la producción se hace a nivel de una - pocas familias, que no consiguen disponer de excedentes suficientes para cambiar las relaciones de producción que se estructuran en su interior. Esto se debe, por una parte, a la pequeña extensión de las tierras y, por otra, a la explotación a que están sujetas por parte de la gran unidad productora. Esta situación impide ampliar la producción, introducir innovaciones tecnológicas y mejorar las condiciones de vida de la población ocupada. 
No es efectivo, como podría parecer, que si el destino de la producción es el comercio exterior, ello haga generar minifundios. La generación del minifundio está vinculada a la existencia de una gran unidad de producción en la región cuyo producto puede estar destinado también al comercio exterior. Lo importante es que por su tamaño y peso en la región, la gran unidad tenga la hegemonía económica, social y política y, al mismo tiempo, realice una política de maximización de sus ganancias mediante el uso especializado de sus tierras. Que los minifundios aparezcan con frecuencia vinculados con el sector de comercio exterior, se debe a que en dicho sector históricamente es donde se pudo o se exigió desarrollar con mayor intensidad grandes unidades de producción. La unidad latifundio-minifundio tiene su explicación no en la ineficiencia económica de la gran propiedad, como muchas veces se ha considerado, sino en la política de máxima eficiencia económica que desarrolla. Puede suceder que cuando surjan situaciones de crisis prolongadas en algunas actividades del comercio exterior, se tornen más evidentes los lazos que unen los latifundios y los minifundios, con la falsa impresión de que los minifundios son fruto de una mala explotación y falta de capacidad de los latifundios para sostener altos niveles de actividad.

Aquí surgen dos interrogantes: ¿cómo se subdivide la tierra para formar los minifundios?, ¿cómo permite el latifundio que los campesinos propietarios se multipliquen a sabiendas que la tierra es la principal fuente de poder y por lo tanto de eventual fortalecimiento de competidores por el poder económico y político?

El problema está en que el minifundio no se forma con la división de tierras de los latifundios productivos. Es fruto sí de una reducción de propiedades privadas grandes y poco eficientes, de propiedades medianas, eficientes o no, y de propiedades comunales sujetas al dominio y a la expansión de las grandes propiedades latifundistas. En este sentido, e[7 latifundio no es la gran propiedad improductiva, sino la gran propiedad eficiente económicamente y que por lo tanto tiene fuerza para expan dirse y avanzar sobre las tierras, la gente y los bienes en su área de influencia.

Conviene señalar de nueva cuenta que la caracterización del minifundio no depende sólo del tamaño de la propiedad, como muchas veces se señala. El minifundio es ante todo una unidad de producción "relativamente" pequeña y que opera bajo condiciones de explotación por otra unidad mayor. El nivel de explotación es tal que el minifundio no consigue apropiarse de excedentes que le posibiliten ampliar su escala de producción e introducir innovaciones tecnológicas que aumenten la productividad del trabajo. Es así como, de manera principal cerca de las grandes ciudades, se multiplican pequeñas unidades agrícolas de producción, no dependientes de un poder comprador monopolizador y por lo tanto menos sujetas a la superexplotación. Esas unidades pequeñas operan por lo común con elevados niveles de productividad y aun cuando 
no tienen la estructura de relaciones de trabajo de tipo capitalista (o sea, trabajo asalariado - pues con frecuencia son propiedades que operan con trabajo de familiares) consiguen disponer de excedentes que posibilitan ampliar la escala de producción, de manera principal a través de la utilización de insumos no tradicionales. Esas unidades de producción naturalmente no pueden ser encuadradas como minifundios; son pequeñas unidades capitalistas y eficientes, especializadas por lo general en productos horti-granjeros. Funcionan como ciertas unidades especializadas de servicios o algunas pequeñas industrias superespecializadas, que prosperan con el desarrollo de la gran industria, sin que compitan con la gran unidad sino en una complementación estructural.

Cabe hablar del problema de las llamadas áreas de frontera agrícola. Son por lo general áreas de expansión del SRME y de destrucción de SRSB. Cuando son áreas de población escasa, los conflictos son menores pero también lo son las ganancias que la expropiación permite al SRME. En esas regiones, también llamadas "pioneras", los procesos de acumulación primitiva se manifiestan con gran eficacia. Lo que no absorbe el SRME lo hace el SRMI. En ciertas situaciones, el avance de la frontera agrícola deja atrás áreas que son transformadas en SRMI y algunas veces por largo tiempo "involucionan" y presentan características de SRSB. Es lo que pasó por ejemplo en áreas del Valle del Parnaíba entre São Paulo y Río de Janeiro con el avance del café en otras regiones. Sólo tiempo después pudo la región integrarse al mercado interno. Lo mismo se puede decir de áreas del Amazonas con el fin del "ciclo de la borracha". En esos períodos la región pierde gran parte de su población. Hay una transferencia de capitales y parte de éste que queda en la región se destruye físicamente o pierde valor por el desuso.

En fecha más reciente, cuando ya el sector urbano adquiere significado mayor, surgen fronteras agrícolas o áreas pioneras no sólo relacionadas con el crecimiento del SRME, sino con el propio SRMI. Este proceso tiene similitudes con el descrito antes en cuanto a la destrucción de las relaciones de producción previamente existentes en la región, con la diferencia que el proceso que se genera tiene una base menos inestable dado que el motor del proceso reposa en el sector urbano interior.

Este modelo funcionó durante mucho tiempo, e incluso debe explicar en gran medida aspectos importantes de la dinámica poblacional reciente en los países de América Latina.

Por último, conviene hacer hincapié en que la subdivisión del sector rural, como se hizo, no significa que se considere a tales subsectores como compartimientos estancos. Todo lo contrario. Están interrelacionados en forma estrecha tanto a través de los flujos de productos como de población. Por supuesto, tales interrelaciones no impiden la existencia de situaciones de dominación, lo que da una orientación a los cambios con el correr del tiempo, al definir un proceso de desarrollo que tiende a la expansión de las relaciones capitalistas de producción por todo el sector rural y la virtual desaparición del SRSB. 
También conviene resaltar que no hay necesariamente una separación rígida entre los tres subsectores, lo que significa de hecho dificultades para "evaluarlos" empíricamente y, de manera principal, para medir los flujos de población a partir de fuentes secundarias. La realidad se presenta como si existiera una superposición espacial de lo que es en realidad una relación estructural.

Por último, puede ser conveniente $o$ indispensable, para efectos analíticos, introducir otras subdivisiones para captar características especificas, en especial las tecnológicas, que van a significar a su vez especificidades en la dinámica de la población. Podría intentarse, por ejemplo, subdividir el sector rural en términos de agricultura propiamente tal y ganadería; producción de alimentos y de materias primas, etc. Entretanto, puede ser conveniente dejar esa nueva subdivisión para otra etapa y que sea resultado del análisis que se efectúe para los tres subsectores básicos por ahora mencionados, o sea: SRSB, SRME y SRMI.

\section{Algunas observaciones adicionales Sobre Brasil y México}

En la etapa de crecimiento acelerado del SRME, en los países que se analizan, aparecen dos situaciones bien distintas. En el caso de México, el crecimiento del SRME, SRMI y del sector rural pudo ocurrir con trans-

\section{Cuadro 14}

Evolución de los contingentes de población EN Brasil y México a

\begin{tabular}{|c|c|c|c|c|c|}
\hline \multicolumn{3}{|c|}{ Brasil } & \multicolumn{3}{|c|}{ México } \\
\hline Fecha & $\begin{array}{l}\text { Poblacion } \\
\text { (miles) }\end{array}$ & $\begin{array}{c}\text { Tasa amual } \\
\text { goometrica }(x)\end{array}$ & Pechs & $\begin{array}{l}\text { Poblacion } \\
\text { (miles) }\end{array}$ & $\begin{array}{c}\text { Tasa amial } \\
\text { gocoft trica }(\phi)\end{array}$ \\
\hline 1800 & 3.6 & & 1800 & 6.5 & \\
\hline 1830 & 5.3 & 3 & 1840 & 7.07 & 0.2 \\
\hline 1850 & 7.2 & , & & & \\
\hline 1872 & 10.0 & 1.5 & & & 1.0 \\
\hline & & 2.1 & 1890 & 11.5 & \\
\hline 1900 & 17.9 & 2.2 & & & 0.7 \\
\hline 1920 & 27.4 & 2 & 1921 & 14.2 & \\
\hline 1940 & 41.2 & 2.0 & 1940 & $19.7 \mathrm{~J}$ & 1.1 \\
\hline
\end{tabular}

Fuente: Hasta 1921, datos citados por: M. Reinhard-A. Armengoud, Historia de la población; Edición Ariel, 1966, p. 331 a 334; Datos de 1940: Censos generales de población; Tasas: Cálculos de cELADE.

a En relación con la llegada de inmigrantes, entre 1820 y 1935, según datos señalados por M. Reinhard-A. Armengoud (op. cit.), ese movimiento es prácticamente nulo para México. Al revés, para el mismo período, Brasil recibe $4.6 \mathrm{mi}-$ llones de personas. Estos 4.6 millones de inmigrantes constituyen la base diferencial de reproducción que elevará, al doble en relación a México, el contingente poblacional brasileño a partir del segundo decenio de este siglo. 
formaciones en el SRSB, constituido por la gran población indígena nativa. En el caso de Brasil, para atender las necesidades de crecimiento del SRME fue necesario echar mano de contingentes de migrantes del exterior, inicialmente de esclavos de África y después de migrantes europeos, lo que rompía los límites internos de transferencia de fuerza de trabajo y de relaciones entre el SRSB y otros sectores (véase por ejemplo las cifras del cuadro 14).

Bajo este aspecto se puede decir que la economía brasileña tuvo un desarrollo capitalista más maduro que en México. En Brasil en términos relativos, el SRSB interno siempre fue bastante reducido en cuanto a contingente de población y de producción en él involucrado. Esta posición superior de Brasil se acredita como real hasta los primeros decenios de este siglo, cuando el violento proceso de reforma agraria en México alteró de manera profunda las condiciones del agro mexicano al destruir viejas estructuras, integrar amplios sectores del territorio y liberar fuerza de trabajo de trabas arcaicas que impedían su acceso al mercado.

Cabe hacer algunas observaciones en cuanto al proceso de maduración de las relaciones capitalistas de producción en México y el sentido que tuvo la reforma agraria en la liberación de fuerza de trabajo para el mercado. El carácter distributivo de la reforma agraria mexicana, que divide el poder de unos cuantos sobre la tierra entre muchas personas, debería operar como elemento de retención de población en el campo y acentuar las diferencias de la dinámica poblacional entre México y Brasil y fortalecer las actividades de subsistencia en la medida que transformaba a los asalariados en pequeños propietarios. Lo que pasó con la reforma agraria en México fue un proceso de muy larga duración y con bastante inestabilidad. En verdad, durante los primeros 30 años de este siglo se habló mucho de la reforma agraria, pero no se efectuó prácticamente nada. La etapa más violenta de la revolución, que fue de 1910 a 1917, tenía la reforma agraria como bandera de lucha y no la práctica inmediata. Aun después de institucionalizada la victoria sobre las fuerzas de Porfirio Díaz y "a pesar de que el espíritu agrarista había articulado las huestes revolucionarias, al entrar México en la etapa de su reconstrucción, subyacía en la conciencia de los primeros gobernantes una evidente resistencia a poner en práctica la política de redistribución de la propiedad agraria, una de las promesas concretas de la lucha social, recién concluida en su etapa armada". ${ }^{7}$

El cuadro 15 muestra la dimensión de lo que se afirma. El área afectada en el período 1915-1934 significa alrededor del 6\% de la superficie del país. Esto sugiere que a pesar de mantener siempre vigente la presión, el debate, la amenaza, el compromiso de la Revolución con el campesinado, esto no se hacía efectivo con la entrega de tierras. Al contrario, se generaba gran inestabilidad en el campo. Fue sólo en el sexenio de 1934 a 1940, bajo la presidencia de Lázaro Cárdenas cuando la entrega de

7 Manuel Aguilera Gómez, op. cit., p. 125. 


\section{Cuadro 15}

MÉxico: Reforma agraria poR Períodos presidenciales

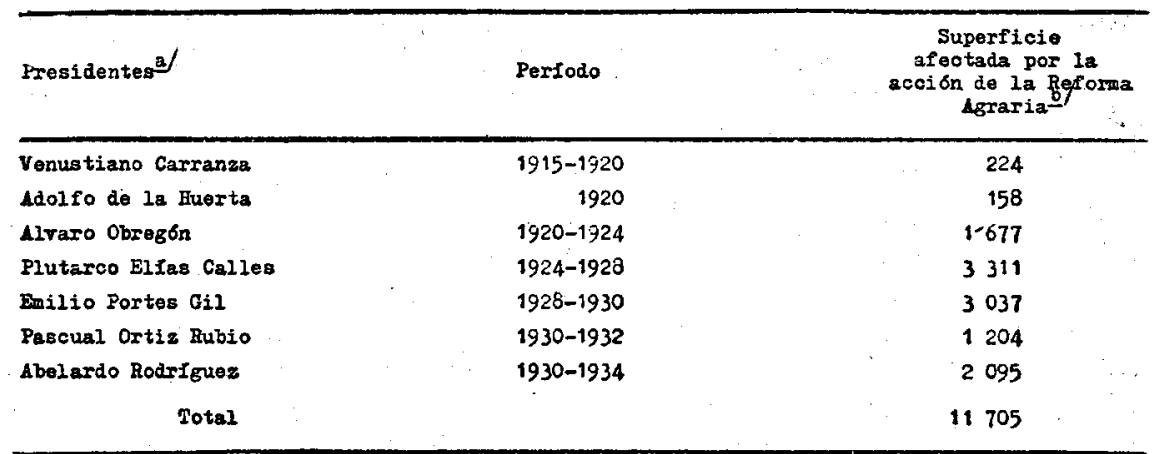

a Datos citados por M. Aguilera Gómez, op. cit., pp. 126, 139 y 144.

b Miles de hectáreas.

tierras a los campesinos se intensificó, y cambió de manera notoria la estructura de relaciones sociales en el campo. En este período, el área afectada por el proceso fue de alrededor de 20 millones de hectáreas o sea, en seis años casi el doble de lo que se haría en los 20 años siguientes. En este período se cumple el carácter redistributivo de la revolución mexicana, y es el más auténtico en cuanto a sus compromisos y su bandera de lucha con el campesinado. Después de 1940 vuelven a manifestarse tendencias conservadoras, al restringirse las medidas observadas en el período anterior. Es así que entre 1940 y 1958 fueron distribuidas 12.3 millones de hectáreas (véase el cuadro 16).

Hay que señalar que no sólo se manifiesta una reducción de los niveles de entrega de tierras, también se desarrollan los llamados latifundios "disfrazados", en donde se distorsiona la naturaleza de la propiedad que de manera formal existe en el área reformada, haciendo que el cambio de orientación del proceso sea más fuerte de 10 que indican las cifras oficiales. Además, con un sistema deficiente de asistencia técnica y financiera al sector reformado, éste acabó transformándose en un sistema

\section{Cuadro 16}

MÉxico: ReForma AGRARIA, 1940-1958 a

\begin{tabular}{llr}
\hline Presidantes & Perlodo & Superficie- \\
\hline Mannel Avila Camacho & $1940-1946$ & 5328 \\
Miguel Momán Valá6s & $1946-1952$ & 3845 \\
Adolfo Ruiz Cortizes & $1952-1958$ & 3199 \\
\hline
\end{tabular}

a Datos citados por M. Aguilera Gómez, op. cit., pp. 126, 139 y 144.

b Miles de hectáreas. 
de minifundio sin conseguir elevar de manera sustancial el nivel de vida de la población campesina. Los 1lamados "ejidos colectivos", que durante el período de Cárdenas tuvieron gran estímulo y perseguían a través del cambio en la estructura de tenencia de tierras beneficiar una gran cantidad de campesinos y no caer en la estructura de minifundio, fueron combatidos con encono tildándolos de que constituian focos de "sovietización" del país. La otra salida posible era distribuir la tierra entre un número menor de personas para constituir unidades de tamaño mediano, y eludir así el minifundismo. Esa solución por supuesto implicaba dejar a muchos sin tierra. En verdad, después de Cárdenas, el debate sobre "ejidos" colectivos o individuales, sobre latifundios y minifundios, sobre ventajas y desventajas de la propiedad privada en oposición a la ejidal, ocupa gran parte de los debates públicos y otros no públicos (por el sentido de tabú que tiene en México lo obrado por la Reforma Agraria). Sin embargo, se define con claridad una tendencia a ponderar la eficiencia del sector privado y a congelar el progreso del sector "ejidal" y atribuir a la tenencia "ejidal" de la tierra males que "objetivamente" se constatan, pero que en mucho son fruto de la propia acción del poder público que opera en muchas ocasiones bajo influencias de grupos sociales no identificados, en su origen, con la revolución campesina y sí frutos del desarrollo capitalista que se manifestó de manera prinçipal en el sector urbano de la economía y que, al paso del tiempo, se constituyó en el polo hegemónico del poder económico y político nacional. Con el fin del período de Cárdenas ese movimiento tomó fuerza. El resultado fue la proliferación de minifundios en el sector reformado sin condiciones para desarrollarse técnicamente. Por otra parte, el sector privado tomó gran impulso, de manera principal las propiedades medianas y grandes, que recibieron facilidades de la banca comercial y apoyo oficial y oficioso del sector público. Además de beneficiarse de sus relaciones con el mercado externo, en especial del sur de Estados Unidos (sobre todo las regiones agrícolas del noroeste, norte y nordeste mexicano) recibieron apoyo técnico y financiero, con el interés no sólo de las ganancias derivadas de las operaciones económicas, sino también con el interés político de desarrollar el sector privado en oposición al ejidal. De esta forma, el desarrollo del sector privado, bajo condiciones privilegiadas, debilita las posiciones del sector reformado y exteriormente le da publicidad a la "eficiencia económica" de aquél. Estos elementos combinados hicieron que en verdad el proceso de reforma agraria en México, en vez de retener población en el campo, estimuló la salida del sector rural al urbano, con lo que la población se comportó de manera semejante a la de Brasil, sin reforma agraria. Esto explica en parte la contradicción señalada antes en cuanto a por qué la reforma agraria mexicana, de carácter redistributivo, no mantuvo la población en el agro.

En conclusión, la supervivencia de precarias condiciones de vida de la población que usufructúa los medios de producción, tanto en los ejidos 
como en las pequeñas propiedades, determina altos niveles de fecundidad, lo cual genera altos niveles de reproducción de la población campesina — dado el control más eficiente de la mortalidad- y mantiene ritmos elevados de transferencia y de disponibilidad de fuerza de trabajo. Esto determinó la formación de un ejército de reserva creciente que presiona sobre los niveles de ingreso de los campesinos ocupados en las medianas y-grandes propiedades agrícolas, lo que implica allí también la persistencia de altas tasas de fecundidad. A su vez, el sector rural influye en los niveles de vida urbanos a través de la migración campo-ciudad y genèraliza para toda la economía pautas de reproducción de niveles elevados.

Lo que sucede en México es semejante a lo que pasa en el Brasil, con la diferencia de que al no haber ejidos ni reforma agraria, se dan con mayor claridad las complejas relaciones entre latifundios y minifundios. También se agregaría el hecho de que en Brasil hay mayores posibilidades para la explotación agrícola y una menor población indígena y, por supuesto, mayor disponibilidad de tierras. Además, la productividad de la agricultura brasileña es bien inferior a la mexicana; pero, sobre todo, hay un nivel bajo o nulo de organización campesina. Lo que esto implique en cuanto a la dinámica de crecimiento de la población, en su manifestación particular de transferencias de fuerza de trabajo del campo a la ciudad en los dos países, es ya un tema en el cual es necesario profundizar y que constituye el centro de nuestras preocupaciones.

\section{BIBLIOGRAFIA}

W. A. Lewis, Economic Development with Unlimited Supplies of Labour, The Manchester School, mayo de 1964.

, Unlimited Supplies of Labour: Further Notes, The Manchester School, enero de 1968.

J. C. H. Fei y G. Ranis, "A Theory of Economic Development”, American Economic Review, 51, septiembre de 1961.

, Development of the Labour Surplus Economy, Homewood Ill., Richard D. Irwin, Inc., 1968.

S. Kuznets, Modern Growth Rate, Structure and Spread, Yale University Press, 1966.

, "Economic Growth and the Contribution of Agriculture: Notes on Measurement", en Eicher y Wits (Comps.), Agriculture in Economic Development, Mc Graw Hill-Book Co., 1964.

T. W. Schultz, Transforming Traditional Agriculture, Yale University Press, 1964.

O. Singer, O Papel do Crecimento Populacional no Desenvolvimento Econômico, São Paulo, Facultade de Higiene e Saude Pública, 1968.

S. L. Barraclough, Notas sobre la tenencia de la tierra, ICIRA, Santiago de Chile, 1970.

W. Pecht, El proceso de transferencia de fuerza de trabajo del campo a la 
ciudad y algunos aspectos de la agricultura mexicana, Santiago de Chile, CELADE, Serie D, Núm. 74, septiembre de 1972.

M. Aguilera Gómez, La reforma agraria en el desarrollo económico de México, México, Instituto Mexicano de Investigaciones Económicas, 1969.

CIDA, Comité Interamericano de Desenvolvimento Agrícola, Tenencia de la tierra $y$ desarrollo del sector agrícola; Brasil, OEA, Washington, D. C., 1966.

\section{ANEXO ESTADISTICO}

Cuadro A-1

SUPERFICIE DE LAS EXPLOTACIONES AGROPECUARIAS, POR APROVECHAMIENTO DE LA TIERRA

(miles de hectáreas)

\begin{tabular}{|c|c|c|c|}
\hline $\begin{array}{l}\text { ripo de aproveotariento } \\
\text { - de las tierras }\end{array}$ & $\begin{array}{l}\text { Brasid } \\
(1960)\end{array}$ & $\begin{array}{l}\text { k6xico } \\
(1960)\end{array}$ & $\begin{array}{l}\text { Es tados } \\
\text { Unidos } \\
\text { (1964) }\end{array}$ \\
\hline Total & 249862.1 & 89992.0 & 449292.7 \\
\hline $\begin{array}{l}\text { Dedicadas a cultiros } \\
\text { permanentes }\end{array}$ & 7797.5 & 1310.1 & $1720.4^{a}$ \\
\hline \multicolumn{4}{|l|}{ De labranza } \\
\hline Con cultiros temporales & $20914.7^{\mathfrak{b} /}$ & 10375.7 & 114384.8 \\
\hline $\begin{array}{l}\text { Fo descanso } \\
\text { Otras clases }\end{array}$ & $\overline{461.6^{c}}$ & $\begin{array}{l}10437.7 \\
1693.4^{d}\end{array}$ & $\begin{array}{ll}22 & 290.9 \\
14 & 100.3^{6}\end{array}$ \\
\hline \multicolumn{4}{|l|}{$\begin{array}{l}\text { Dodicadas a praderas y pas } \\
\text { tigulea permanentes }\end{array}$} \\
\hline Pastos cultirados & 20063.3 & $\ldots$ & 23237.4 \\
\hline Pastos naturalos & 102272.1 & - & 198437.2 \\
\hline Tierras en montes o bosques & 57945.1 & 43678.6 & $59076.7^{5}$ \\
\hline Tierras de otras clases & $40407.9^{\mathrm{B}}$ & $22496.4^{\frac{b}{6}}$ & 16055.0 \\
\hline
\end{tabular}

Fuente: América en cifras, 1972. Situación económica, Washington, oEA, cuadro 31102 , p. 4.

a Comprende las superficies plantadas con frutas, nueces, uvas y café.

b Incluye aquellas tierras en descanso cuya utilización estaba prevista dentro del año siguiente a la fecha del censo.

c Tierras irrigadas.

d Corresponde a la superficie de cultivos perdidos.

- Comprende 11552256 hectáreas con cosechas para mejoramiento de la tierra y 2547995 hectáreas de cultivos perdidos.

f Incluye 33270249 hectáreas de bosques con pastos.

- Comprende 28147799 hectáreas de tierras no cultivadas (incluso en descanso) y 12233133 hectáreas con tierras improductivas.

h Incluye superficie para la agricultura y ganadería no aprovechada. 


\section{Cuadro A-2}

NÚMERO Y SUPERFICIE DE LAS EXPLOTACIONES AGROPECUAARIAS SEGÚN TAMAÑo DE LA EXPLOTACIÓN, 1960

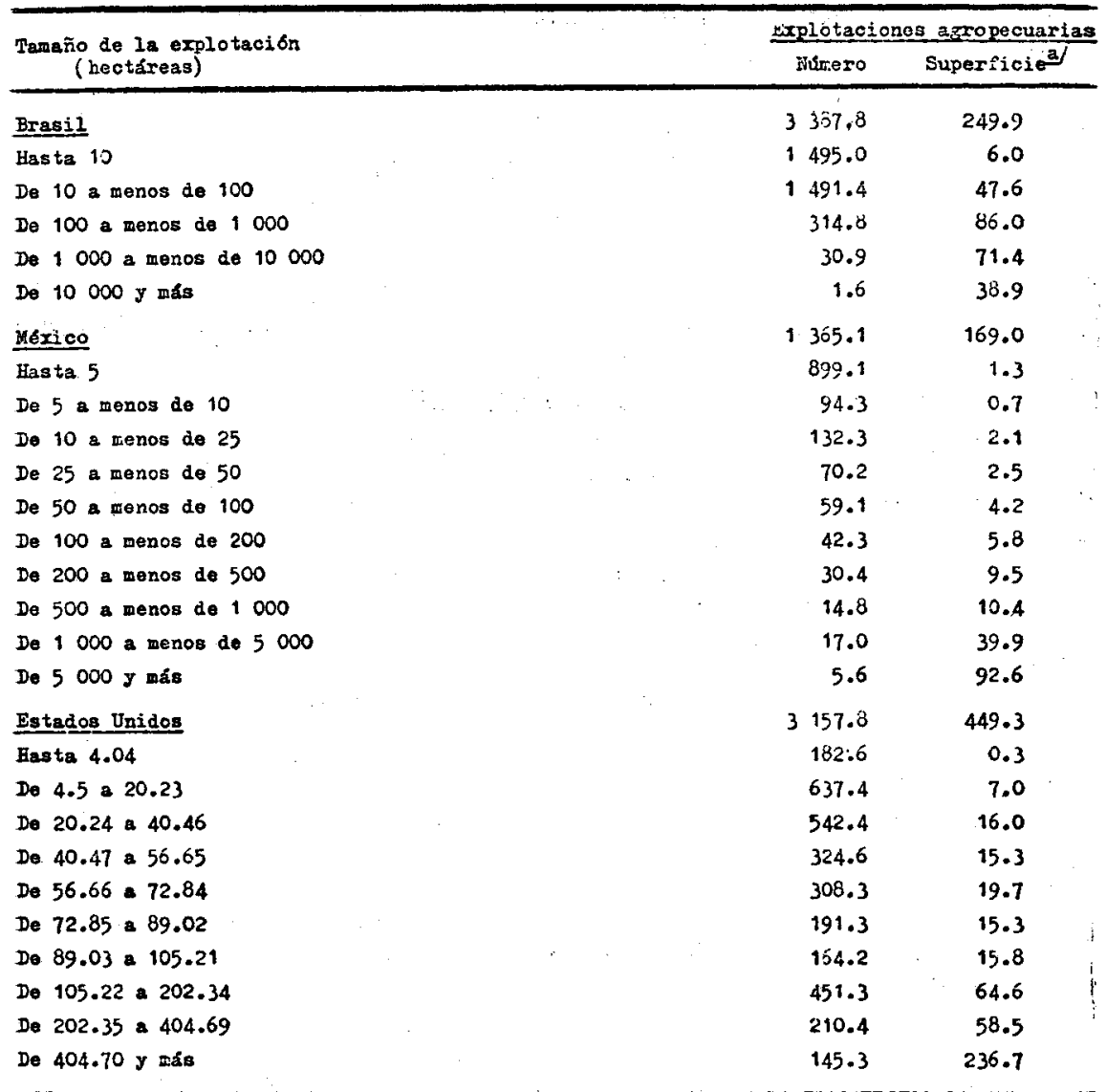

Fuente: América en cifras, 1972. Situación económica, cuadro 311-04.

a Miles de hectáreas. 
Cuadro A-3

NÚMERO $Y$ SUPERFICIE DE LAS EXPLOTACIONES AGROPECUARIAS, POR RÉGIMEN DE TENENCIA

\begin{tabular}{|c|c|c|c|c|c|c|}
\hline \multirow[b]{2}{*}{ Régimen de tenencie } & \multicolumn{2}{|c|}{ Brasil } & \multicolumn{2}{|c|}{ Merico } & \multicolumn{2}{|c|}{ Eatados Unidos } \\
\hline & (miles) & Superficio & $\begin{array}{l}\text { wisero } \\
\text { (miles) }\end{array}$ & Superficiog & $\begin{array}{l}\bar{N} \text { inero } \\
\text { (miles) }\end{array}$ & Superficio \\
\hline $\begin{array}{l}\text { Con un soio IEgimen } \\
\text { de tenencia }\end{array}$ & , & & & . & & \\
\hline Fropies del productor & 2328.0 & 212.1 & 1289.9 & 97.0 & 1818.3 & 129.1 \\
\hline Arrendadas & 575.9 & 17.9 & 33.8 & 7.5 & 539.9 & 58.6 \\
\hline Doupadas sin titulo & 356.5 & 9.1 & 5.3 & 3.3 & - & - \\
\hline Bajo formas colectiras & - & - & 18.7 & $44.5^{\mathrm{b} /}$ & - & $\because$ \\
\hline $\begin{array}{l}\text { Bajo otros rezimenes } \\
\text { aimples }\end{array}$ & - & - & 17.4 & $16.8^{\mathrm{e} /}$ & 17.8 & / لd. \\
\hline $\begin{array}{l}\text { Con régimenes de tenencia } \\
\text { mixtos }\end{array}$ & 77.4 & 10.8 & - & - & 781.9 & $215.7^{\oplus /}$ \\
\hline Total & 3337.8 & 249.9 & 365.1 & 169.1 & 3157.9 & 449.3 \\
\hline
\end{tabular}

Fuente: América en cifras, 1970. Situación económica, 1. Agricultura, ganadería, silvicultura, caza y pesca, Washington, OEA, 1970, cuadro 311.02 .

a Millones de hectáreas.

t Predios operados por el "Presidente del Comisariado Ejidal".

c Comprende predios operados por el "Presidente de la Comunidad".

d Explotaciones operadas por "administradores".

e Explotaciones operadas por "propietarios arrendatarios". 